\title{
Tests and Analysis on Thermal Expansion Behaviour of Steel Strand used in Prestressed Concrete Structure under Low Temperatures
}

\author{
Jian $X_{i e^{1,2)}}$, and Jia-Bao Yan ${ }^{1,2), *}$ \\ (Received November 27, 2016, Accepted January 7, 2018)
}

\begin{abstract}
This paper presents the results of the tests and analysis on the coefficient of thermal expansion for the steel strand under combined low temperatures and prestressing forces. A test program was firstly carried out to study the thermal expansion behaviour of the seven-wire strand under combined different low temperatures ranging from 20 to $-165{ }^{\circ} \mathrm{C}$ and different prestressing levels ranging from 0 to $0.75 f_{\mathrm{t}} / f_{\mathrm{tk}}$. The test results exhibited the thermal expansion behaviours of the steel strand under low temperatures in terms of thermal strain versus temperature curves, transit linear thermal expansion coefficient, and average thermal expansion coefficient. The influences of the low temperature and prestressing levels on the thermal expansion behaviours of the steel strand were separately discussed and analysed. Based on the test data, mathematical models were developed to predict the thermal expansion coefficients including transit and average of the steel strand. The developed regression models fully considered the influences of the low temperature and prestressing stresses acted on the strand. Finally, design equations were proposed to predict the transit and average thermal expansion coefficient of the steel strand under combined low temperature and prestressing forces.
\end{abstract}

Keywords: cryogenic temperature, steel strand, thermal expansion coefficient, transit linear expansion coefficient, thermal strain, arctic structure, prestressed concrete structure, material properties, LNG container.

\section{Nomenclature}

$\mathrm{L}_{0} \quad$ Length of the steel strand at ambient temperature level $T_{0}$

$\mathrm{L}_{1} \quad$ Length of the steel strand at temperature level $T_{1}$

$\mathrm{L}_{2} \quad$ Length of the steel strand at temperature level $T_{2}$

$T_{1}, T_{2}$ Temperature of the steel strand at state 1 and 2

$R^{2} \quad$ Correlation coefficient

$S \quad$ Standard error of the regression

$f_{t} \quad$ Prestressing force applied on the steel strand

$f_{t k} \quad$ Ultimate tensile resistance of the steel strand

$\alpha_{m} \quad$ Average linear expansion coefficient of the steel strand

$\alpha_{t} \quad$ Transit linear expansion coefficient of the steel strand

$\beta_{P} \quad$ Ratio of prestressing level, equals $\mathrm{f}_{t} / \mathrm{f}_{t k}$

\section{Abbreviations}

COV Coefficient of variation

LNG Liquid natural gas

\footnotetext{
${ }^{1)}$ School of Civil Engineering, Tianjin University, Tianjin 300072, China.

*Corresponding Author; E-mail: ceeyanj@163.com

${ }^{2)}$ Key Laboratory of Coast Civil Structure Safety of Ministry of Education, Tianjin University, Ministry of Education, Tianjin 300072, China.

Copyright $\odot$ The Author(s) 2018. This article is an open access publication
}

LVDT Linear varying displacement transducer

PCP Restressed concrete

RC Reinforced concrete

\section{Introduction}

Recently, as the needs on oil and gas keep increasing, the explorations of the oil and gas has been extended to the Arctic region since this region stores $13 \%$ of the world's undiscovered oil and 30\% gas (Yan et al. 2014). Different types of offshore or onshore platforms were built for the exploration of the oil and gas (Palmer and Croasdale 2013), e.g., jacket structure, gravity based structure, and even artificial island. Most of these Arctic engineering constructions were made of reinforced concrete (RC) structure or prestressed concrete (PC) structure. During their service lives, all these PC or RC structures suffer harsh environment with low temperatures. Another scenario of the PC or RC structures under critical low temperature occurs to the container for the liquid natural gas (LNG) when the leakage of $\mathrm{LNG}$ took place. Due to the increasing consumptions of the LNG, more and more PC LNG containers have been built and put into use. Since these Arctic RC or PC structure and PC LNG containers were exposed to low temperature, the mechanical properties of the steel strand used in the RC or PC structures need to be carefully determined for the evaluation on their structural performances. 
Planas et al. (1988) experimentally studied the mechanical properties of the steel strand under temperatures of 20 and $-165{ }^{\circ} \mathrm{C}$ that included yield strength, ultimate strength, and fracture strains. The mechanical properties of the steel strand under low temperature ranging from 20 to $-165^{\circ} \mathrm{C}$ has been reported by Nie (Nie 2012). The thermal expansion coefficients of the steel reinforcement used in the PC structure were experimentally studied by Elices et al. (Elices et al. 1982, 1986). The geometrically nonlinear behaviour of the strand has been reported by Gasparion and Gautam (2002). Liu et al. (2007) reported the linear expansion factor of strand used for the water-heated instruments under elevating temperature. Chen and Liu (2010) continued the experimental study on the thermal expansion factor of the cables used in the spatial structures. Sun et al. (2011) analytically and experimentally investigated the thermal expansion mechanism of the steel cables under the natural environmental temperatures. However, most of the previous experimental studies focused on the mechanical properties of the steel strand or reinforcements under low temperatures. The information on the thermal expansion of the steel strand under low temperatures ranging from 20 to $-165^{\circ} \mathrm{C}$ is still quite limited.

The thermal expansion coefficient of the constructional steel was usually taken as $1.2 \times 10^{-5} /{ }^{\circ} \mathrm{C}$ in most of the design codes. The thermal expansion coefficient for the steel cable or strand varied slightly from that of the constructional steels. $1.15 \times 10^{-5} /{ }^{\circ} \mathrm{C}$ was used in ASCE standard (1996). In Eurocode 3 (1993) and Japanese Steel Structure Association (1994), this coefficient was specified as $1.2 \times 10^{-5} /{ }^{\circ} \mathrm{C}$ for the steel material. In AISC (1994), the thermal expansion coefficient for the steel strand was taken as $(11.09+0.0062 \mathrm{~T}) \times 10^{-6} /{ }^{\circ} \mathrm{C}$. In Fib Model 2010 (International Federation for Structural Concrete 2010), the coefficient of thermal expansion for steel was taken as $10 \times 10^{-6} /{ }^{\circ} \mathrm{C}$ for the temperature range between -20 and $180{ }^{\circ} \mathrm{C}$. However, these specifications have limitations on the thermal expansion coefficient of steel, and they were not applicable to the steel strand under combined low temperatures to about $-180{ }^{\circ} \mathrm{C}$ and different prestressing levels. Thus, it is still of interest to perform the experimental studies on the steel strand to obtain the necessary information on their thermal expansion behaviours under different low temperature levels and prestressing levels. The information obtained in this study will offer basic information as the inputting data for the analysis on the structural behaviours of the RC or PC structures with steel strand under combined low temperatures and different loading scenarios. These studies would definitely contribute to the design of the RC or PC structures with these steel strands at different low temperatures.

This paper reported the experimental studies on the thermal expansion behaviours of the steel strands under different low temperatures and prestressing levels. Considering the steel strand in PC structures is pre-stressed to different stress levels, the represetative prestressing levels used in the PC structures were chosen, i.e., $0,0.4,0.5,0.65,0.75$ times $f_{\text {tk }}$ ( $f_{t k}$ denotes ultimate tensile resistance of the steel strand). At each prestressing level, the coefficients of thermal expansion under different temperature levels were tested. The thermal expansion strain versus low temperature or prestressing level relationships were reported. Based on these test data, regression analysis were carried out to develop the mathematical models to predict the linear expansion strain at different low temperature and prestressing stress. Finally, the empirical design formulae on the coefficients of thermal expansion were recommended for the steel strands under different loading levels and low temperatures ranging from 20 to $-180{ }^{\circ} \mathrm{C}$.

\section{Tests on Thermal Expansion Coefficient of Steel Strand Under Low Temperature}

\subsection{Specimens}

This test program adopted seven-wire strand that was widely used in the PC structure. The geometric and mechanical properties of the strand included (1) the diameter of the strand is $15.2 \mathrm{~mm}$, and the length of the steel strand is $1000 \mathrm{~mm}$; (2) the yield strength, elastic Young's modulus, and fracture strain of the strand are $1860 \mathrm{MPa}, 198 \mathrm{GPa}$, and 0.05 , respectively; (3) the ultimate tensile resistance of the strand is $264.2 \mathrm{kN}$.

Considering different prestressing levels influence the thermal expansion coefficient, five prestressing levels were applied to the steel strand specimens, i.e., $0 f_{\mathrm{tk}}, 0.4 f_{\mathrm{tk}}, 0.5 f_{\mathrm{tk}}$, $0.65 f_{\mathrm{tk}}, 0.75 f_{\mathrm{tk}}\left(f_{\mathrm{tk}}\right.$ denotes the ultimate tensile resistance of the seven-wire strand). Thus, the specimens can be categorized into five groups namely A-E. Each group contains three identical specimens. All the specimens were prepared according to Chinese standard GB/T 4339 (National Standard of the People's Republic of China 2008). Table 1 lists the details of these testing specimens.

\subsection{Test setup and measurements}

The testing procedures on the thermal expansion included the cooling (or heating) process, maintaining process, loading and measuring process. In order to realize the simulation of the low temperature testing environment, a cooling chamber was used. Figure 1 shows the test setup for the coefficient of the thermal expansion of the steel strand under combined different prestressing levels and low temperatures. Liquid nitrogen was injected into the cooling chamber through an electromagnetic valve to achieve the low temperature environment. Insulation measures were taken to cover the cooling chamber to isolate the heat transfer from the environment to the cooling chamber. Since the prestressing level would brought influences on the thermal expansion coefficient of the steel strand, hydraulic jack was used to apply the prestress to the strand in the cooling chamber.

During each test, the steel strand was firstly put into the cooling chamber and installed on the reaction frame. Followed, prestressing was carried out to the steel strand by the hydraulic jack. Considering the contracting stress due to the low temperature, a gap of $30 \mathrm{kN}$ to each target presressing 
Table 1 Details of the sepcimens.

\begin{tabular}{|c|c|c|c|c|c|}
\hline Item & Temperature range $\left({ }^{\circ} \mathrm{C}\right)$ & $\begin{array}{l}\text { Initial prestressing } \\
\text { ratio, } f_{\mathrm{t}} / f_{\mathrm{tk}}\end{array}$ & Item & Temperature range $\left({ }^{\circ} \mathrm{C}\right)$ & $\begin{array}{l}\text { Initial prestressing } \\
\text { ratio, } f_{\mathrm{t}} / f_{\mathrm{tk}}\end{array}$ \\
\hline A1 & 20 to -165 & 0 & $\mathrm{C}-3$ & 20 to -165 & 0.5 \\
\hline $\mathrm{A} 2$ & 20 to -165 & 0 & D-1 & 20 to -165 & 0.65 \\
\hline $\mathrm{A} 3$ & 20 to -165 & 0 & D-2 & 20 to -165 & 0.65 \\
\hline $\mathrm{B} 1$ & 20 to -165 & 0.4 & D-3 & 20 to -165 & 0.65 \\
\hline B2 & 20 to -165 & 0.4 & E-1 & 20 to -165 & 0.75 \\
\hline B3 & 20 to -165 & 0.4 & $\mathrm{E}-2$ & 20 to -165 & 0.75 \\
\hline $\mathrm{C} 1$ & 20 to -165 & 0.5 & E-3 & 20 to -165 & 0.75 \\
\hline $\mathrm{C} 2$ & 20 to -165 & 0.5 & & & \\
\hline
\end{tabular}

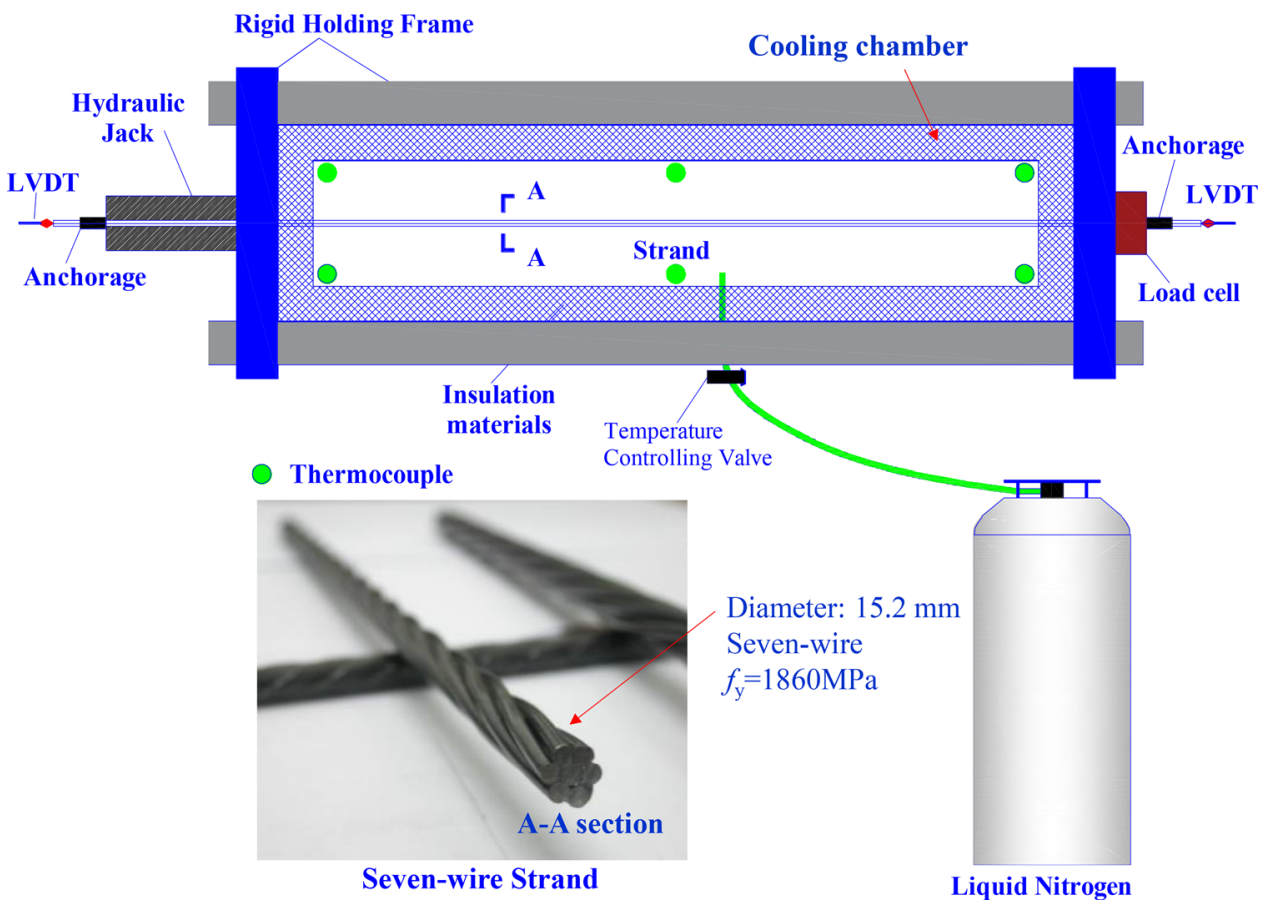

Fig. 1 Test setup on thermal expansion of steel strand under different pre-stressing levels and low temperatures.

level was reserved for the test before the cooling process. After the prestressing on the strand, liquid nitrogen was injected into the cooling chamber. Six thermal couples were averagely distributed on the surface of the steel strand to monitoring its temperature. After achieving the target temperature of $-165^{\circ} \mathrm{C}$, the injection of the liquid nitrogen will be controlled to maintain this temperature level. Then, the steel strand was prestressed to the target prestressing levels, and this prestressing level was maintained during the thermal expansion behaviour test. After that, the temperature in the cooling chamber will be gradually increased to the ambient temperature step-by-step. During this heating process, linear varying displacement transducers (LVDTs) were used to monitor the displacements at the two ends of the steel strand as shown in Fig. 1. All the readings of the sensors including the thermocouples, load cell, and LVDTs were monitored and recorded by software running on the PC during the testing.

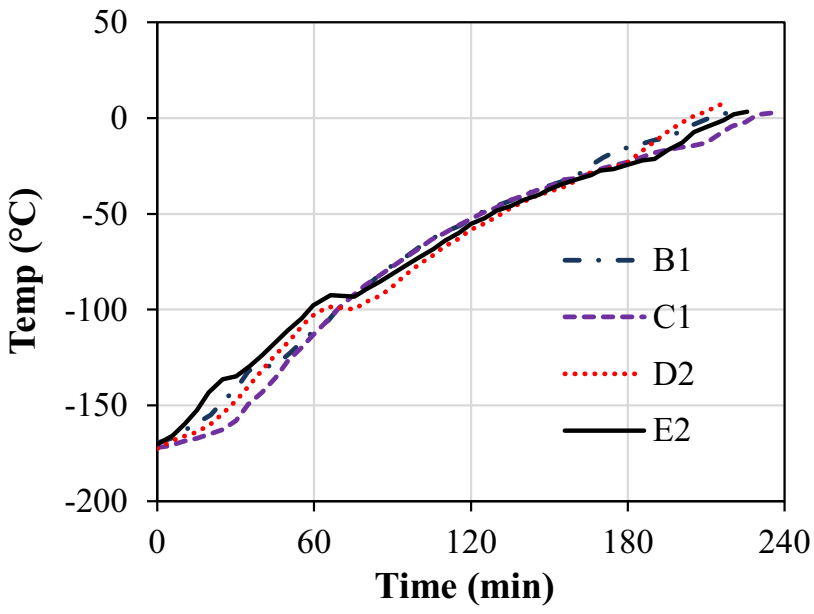

Fig. 2 Temperature versus time relationship during heating process. 
One point needs to be addressed is that the heating rate needs to be strictly controlled during the tests. Figure 2 shows the measured low temperature versus testing time relationship of the representative specimens. It can be seen that the heating rate equals about $0.8{ }^{\circ} \mathrm{C} / \mathrm{min}$ that is still within the limitations of maximum cooling rate of $3{ }^{\circ} \mathrm{C} / \mathrm{min}$ for the tests on the thermal expansion coefficient of steel product (National Standard of the People's Republic of China 2008).

\section{Test Results and Discussions}

\subsection{Temperature Versus Thermal Strain Behaviour}

During the testing process, the thermal strains of the steel strand were measured. Figure 3 shows the thermal strain versus the temperature relationship for the steel strand under different prestressing levels. These figures show that there were two working stages for the development of the thermal strain as the temperature increases from -165 to $0{ }^{\circ} \mathrm{C}$. At stage I, i.e., temperature interval from -80 to $0{ }^{\circ} \mathrm{C}$, the contracting thermal strain increases almost linearly with the increase of the temperature. At stage II, i.e., temperature interval from -165 to $-80{ }^{\circ} \mathrm{C}$, the thermal strain increases nonlinearly with the increase of the temperature. This nonlinear behaviour may be caused by the change of the micro structures of the steel strand under low temperature below $-80{ }^{\circ} \mathrm{C}$. Previous experimental studies on the mechanical properties of the mild steel under low temperature (Yan and Xie 2017) showed that as the temperature reduced below $-80{ }^{\circ} \mathrm{C}$ the failure mode of the mild steel changed from ductile mode to the brittle mode. This might lead to the change of the increasing rate of the thermal strain with the temperature.

Secondly, these figures also showed that the thermal strain increase with the increase of the prestressing forces applied on the steel strand. Figure 4 plots thermal strain of the steel strand under certain temperature levels with different

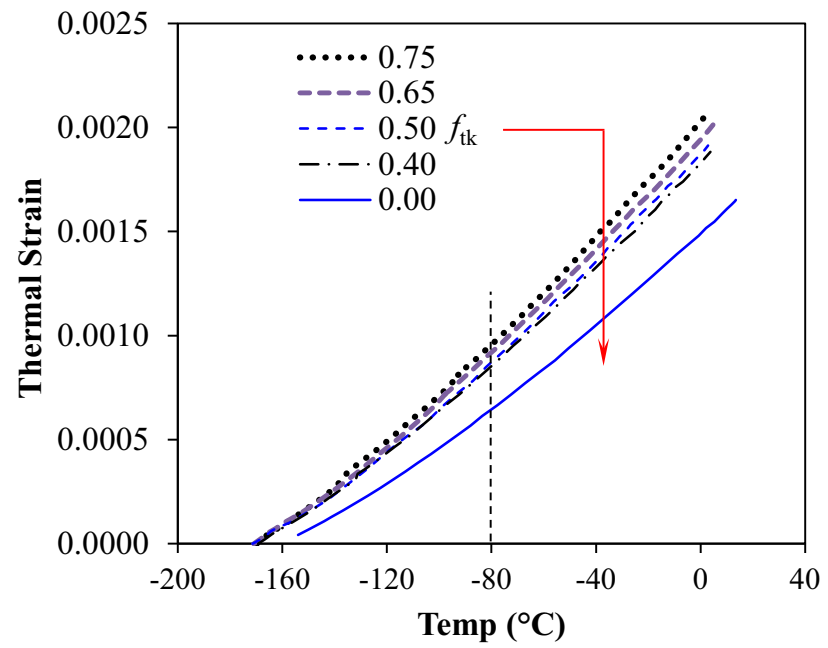

Fig. 3 Temperature versus thermal strain relationship during heating process.

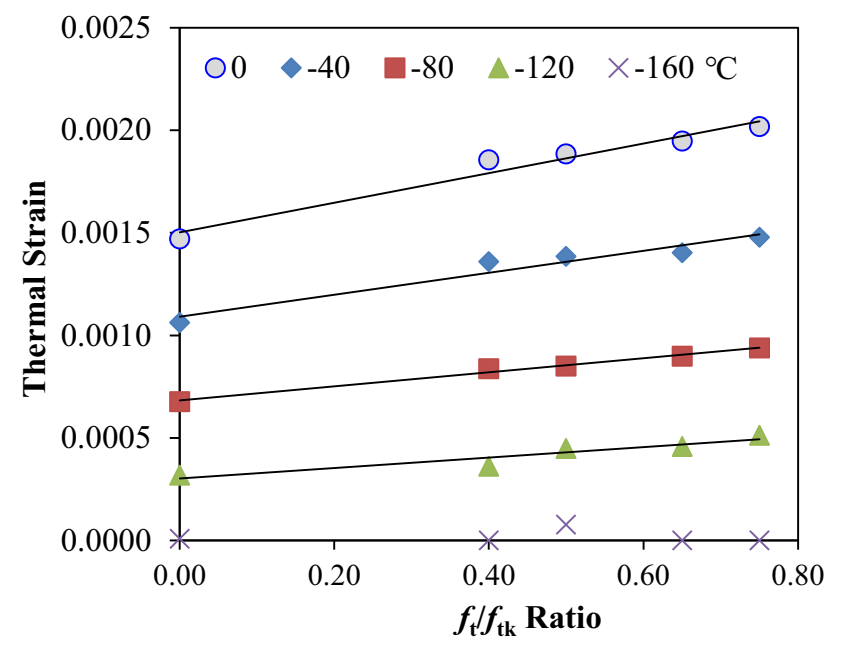

Fig. 4 Prestressing level versus thermal strain relationship during heating process.

prestressing forces. It can be seen that at certain fixed temperature the thermal strain of the steel strand increases almost linearly with the increase of the prestress in the strand. This is because that the prestressing accelerates flow of metals as well as the temperature does.

\subsection{Transit Linear Expansion Coefficient of Steel Strand}

The transit linear expansion coefficient was used to describe the thermal expansion at certain time point. According to Chinsese code GB/T4339-2008 (National Standard of the People's Republic of China 2008), the transit linear expansion coefficient of the steel material is defined as the following

$$
\alpha_{t}=\frac{1}{L_{i}} \lim _{T_{2} \rightarrow T_{1}} \frac{L_{2}-L_{1}}{T_{2}-T_{1}}=(d L / d T) / L_{i} \quad T_{1}<T_{i}<T_{2}
$$

where, $\alpha_{\mathrm{t}}$ denotes the transit linear expansion coefficient, in / ${ }^{\circ} \mathrm{C} ; L_{1}$ denotes the length of the steel strand at temperature level $T_{1}$, in $\mathrm{mm} ; L_{2}$ denotes the length of the steel strand at temperature level $T_{2}$, in $\mathrm{mm} ; T_{1}, T_{2}$ denote temperature, in ${ }^{\circ} \mathrm{C}$

Figure 5 shows the representative scatters of the transit linear expansion coefficient at different low temperatures for the steel strand under different prestressing levels.

The transit linear thermal expansion coefficients of three identical specimens are listed in Table 2. These figures and table show that (1) the transit linear expansion coefficient of the steel strand increases almost linearly with the increase of the temperature; (2) the transit linear expansion coefficient exhibits strong correlation with the low temperature, i.e., the correlation coefficients $R^{2}$ are larger than 0.5 and in some cases the $R^{2}$ values are even close to $0.9 ;(3)$ the transit linear thermal expansion coefficient increases with the increase of the pre-stress applied in the steel strand. This is because the low temperature reduces the molecular translational energy that reduce the activity of atomic and more molecular translational energy will be required for the heat transfer, which results in the reduction of the transit linear expansion 


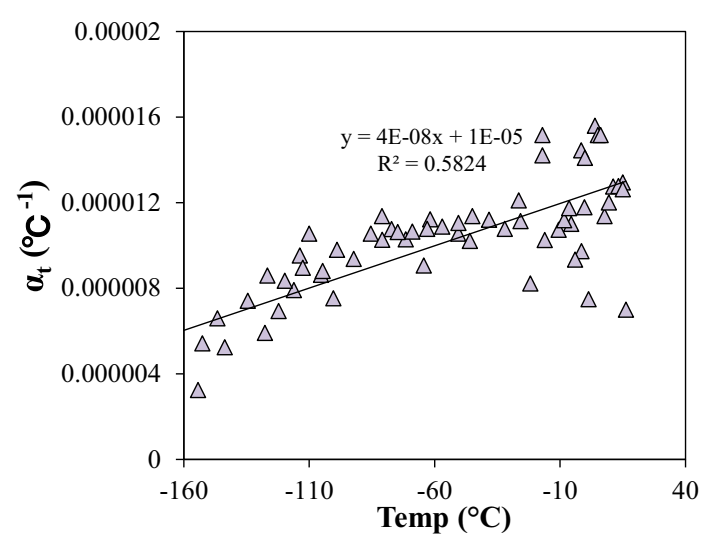

(a) A2

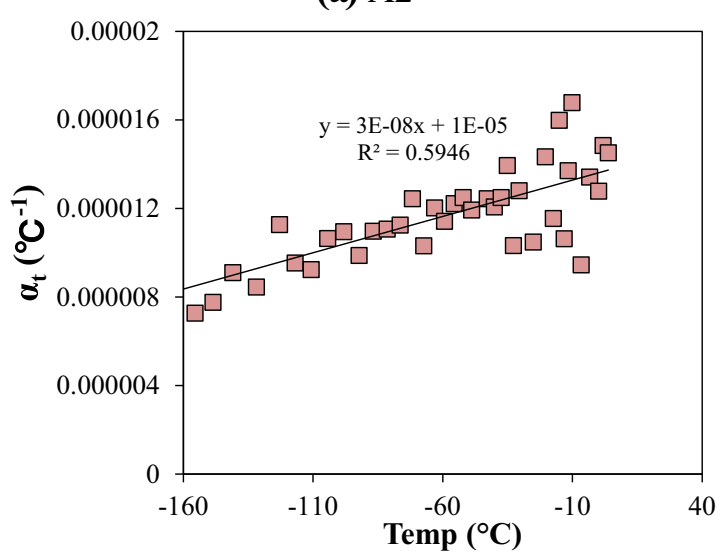

(c) B1

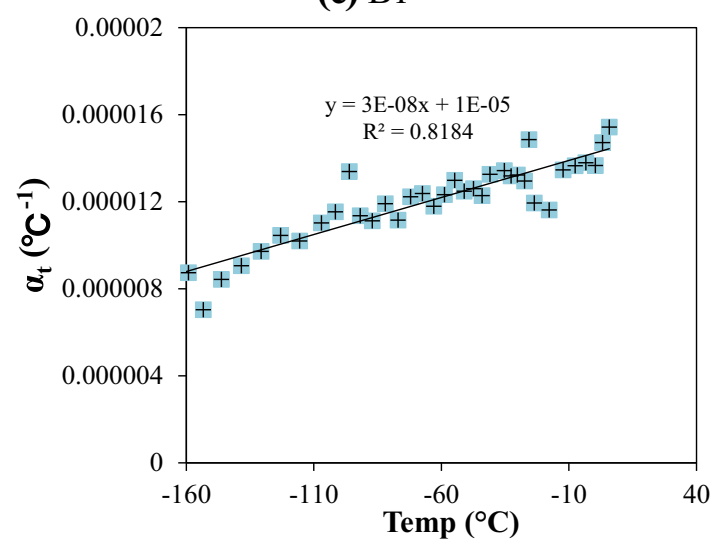

(e) D2

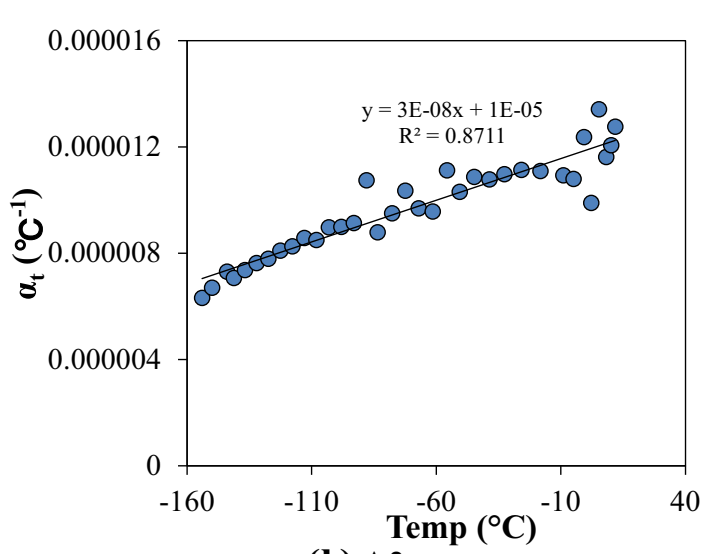

(b) A3

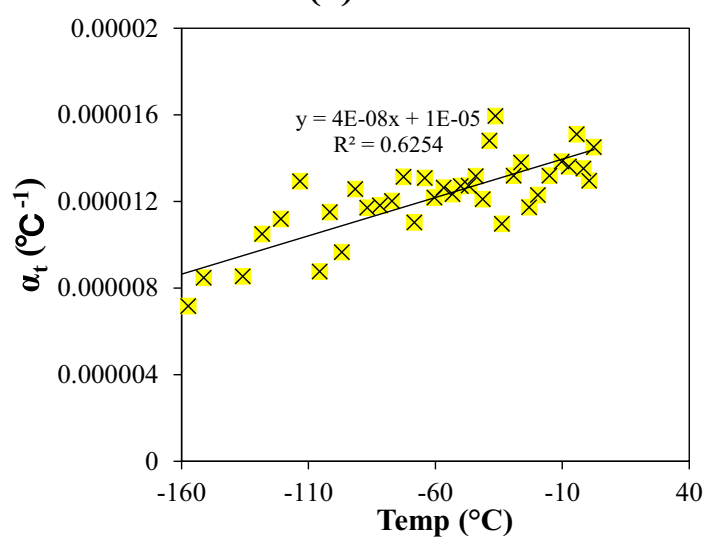

(d) $\mathrm{C} 2$

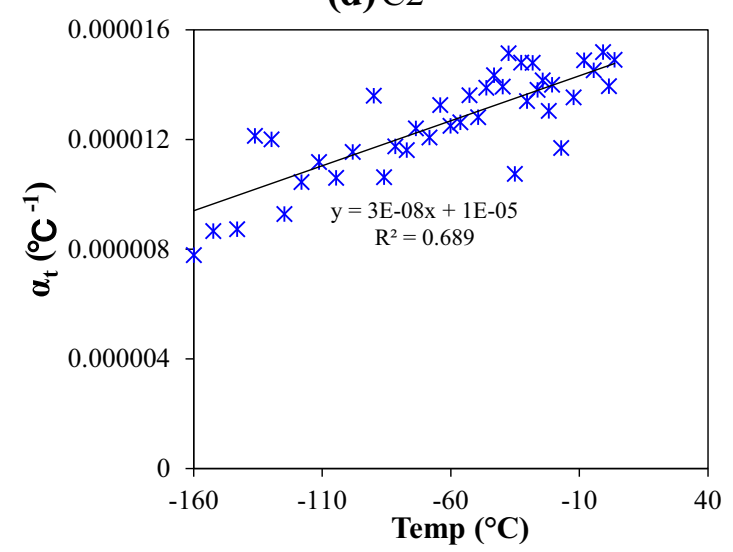

(f) $\mathrm{E} 2$

Fig. 5 Scatters of transit linear expansion coefficient versus temperature relationship.

coefficients. Meanwhile, the prestressing on the strand enhanced the connections between the different components in the metal that speeds up the flow of the metal. All these improved the thermal expansion factor of the steel strand.

Thus, in the analysis on the transit linear expansion coefficient of the steel strand, the low temperature levels and prestressing levels are two key parameters that need to be considered and calibrated.

\subsection{Average Linear Expansion Coefficient}

In Chinsese code GB/T4339-2008 (National Standard of the People's Republic of China 2008), the average linear expansion coefficient of the steel material is defined as the following

$$
\alpha_{\mathrm{m}}=\frac{L_{2}-L_{1}}{L_{0}\left(T_{2}-T_{1}\right)}=\frac{\Delta L}{L_{0} \times \Delta T}
$$

where, $\alpha_{\mathrm{m}}$ denotes average linear expansion coefficient, in/ ${ }^{\circ} \mathrm{C} ; L_{1}$ denotes the length of the steel strand at temperature level $T_{1}$, in $\mathrm{mm} ; L_{2}$ denotes the length of the steel strand at temperature level $T_{2}$, in $\mathrm{mm} ; T_{1}, T_{2}$ denote temperature, in ${ }^{\circ} \mathrm{C} ; L_{0}$ denotes the length of the steel strand at ambient temperature of $T_{0}=20^{\circ} \mathrm{C}$.

Thus, the average linear coefficients could be calculated by Eq. (2) as listed in Table 3. Figure 6 shows the scatters of the transit linear expansion coefficient versus temperature relationship for steel strand under different prestressing levels. It can be seen that the average linear coefficient of the 
Table 2 Transit linear expansion coefficients for steel strands under different low temperature and prestressing stress.

\begin{tabular}{|c|c|c|c|c|c|c|c|c|c|c|c|c|c|}
\hline \multirow[t]{2}{*}{$T\left({ }^{\circ} \mathrm{C}\right)$} & \multirow[t]{2}{*}{$\mid f_{\mathrm{t}} / f_{\mathrm{tk}}$ ratio } & \multicolumn{5}{|c|}{$\alpha_{t}$ in Group A $\left(\times 10^{-6} /{ }^{\circ} \mathrm{C}\right)$} & \multirow[t]{2}{*}{$T\left({ }^{\circ} \mathrm{C}\right)$} & \multirow[t]{2}{*}{$\mid f_{\mathrm{t}} / f_{\mathrm{tk}}$ ratio } & \multicolumn{5}{|c|}{$\alpha_{\mathrm{t}}$ in Group B $\left(\times 10^{-6} /{ }^{\circ} \mathrm{C}\right)$} \\
\hline & & A1 & A2 & A3 & Mean & C.O.V. & & & B1 & $\mathrm{B} 2$ & B3 & Mean & C.O.V. \\
\hline 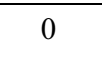 & 0.00 & 11.5 & 12.3 & 11.5 & 11.8 & 0.04 & 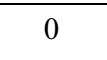 & 0.40 & 13.5 & 13.7 & 13.7 & 13.6 & 0.01 \\
\hline-20 & 0.00 & 11.0 & 11.6 & 11.0 & 11.2 & 0.03 & -20 & 0.40 & 12.9 & 13.1 & 13.0 & 13.0 & 0.01 \\
\hline-40 & 0.00 & 10.4 & 10.9 & 10.4 & 10.6 & 0.03 & -40 & 0.40 & 12.3 & 12.5 & 12.4 & 12.4 & 0.01 \\
\hline-60 & 0.00 & 9.8 & 10.2 & 9.8 & 10.0 & 0.02 & -60 & 0.40 & 11.7 & 11.8 & 11.8 & 11.8 & 0.01 \\
\hline-80 & 0.00 & 9.3 & 9.6 & 9.3 & 9.4 & 0.02 & -80 & 0.40 & 11.1 & 11.2 & 11.1 & 11.1 & 0.00 \\
\hline-100 & 0.00 & 8.7 & 8.9 & 8.7 & 8.8 & 0.01 & -100 & 0.40 & 10.5 & 10.5 & 10.5 & 10.5 & 0.00 \\
\hline-120 & 0.00 & 8.2 & 8.2 & 8.2 & 8.2 & 0.00 & -120 & 0.40 & 9.9 & 9.9 & 9.8 & 9.9 & 0.00 \\
\hline-140 & 0.00 & 7.6 & 7.5 & 7.6 & 7.6 & 0.01 & -140 & 0.40 & 9.3 & 9.3 & 9.2 & 9.2 & 0.00 \\
\hline-165 & 0.00 & 6.9 & 6.7 & 6.9 & 6.8 & 0.02 & -165 & 0.40 & 8.5 & 8.5 & 8.4 & 8.5 & 0.01 \\
\hline \multirow[t]{2}{*}{$T\left({ }^{\circ} \mathrm{C}\right)$} & \multirow[t]{2}{*}{$f_{\mathrm{t}} / f_{\mathrm{tk}}$ ratio } & \multicolumn{5}{|c|}{$\alpha_{\mathrm{t}}$ in Group $\mathrm{C}\left(\times 10^{-6} /{ }^{\circ} \mathrm{C}\right)$} & \multirow[t]{2}{*}{$T\left({ }^{\circ} \mathrm{C}\right)$} & \multirow[t]{2}{*}{$\mid f_{\mathrm{t}} / f_{\mathrm{tk}}$ ratio $\mid$} & \multicolumn{5}{|c|}{$\alpha_{\mathrm{t}}$ in Group $\mathrm{D}\left(\times 10^{-6} /{ }^{\circ} \mathrm{C}\right)$} \\
\hline & & $\mathrm{C} 1$ & $\mathrm{C} 2$ & $\mathrm{C} 3$ & Mean & C.O.V. & & & D1 & $\mathrm{D} 2$ & D3 & Mean & C.O.V. \\
\hline 0 & 0.50 & 14.1 & 14.3 & 13.8 & 14.1 & 0.02 & 0 & 0.65 & 14.8 & 14.2 & 14.1 & 14.4 & 0.03 \\
\hline-20 & 0.50 & 13.4 & 13.6 & 13.2 & 13.4 & 0.02 & -20 & 0.65 & 14.1 & 13.6 & 13.5 & 13.7 & 0.02 \\
\hline-40 & 0.50 & 12.7 & 12.9 & 12.6 & 12.7 & 0.01 & -40 & 0.65 & 13.4 & 12.9 & 12.9 & 13.1 & 0.02 \\
\hline-60 & 0.50 & 12.0 & 12.2 & 12.0 & 12.0 & 0.01 & -60 & 0.65 & 12.8 & 12.3 & 12.3 & 12.4 & 0.02 \\
\hline-80 & 0.50 & 11.3 & 11.4 & 11.4 & 11.4 & 0.01 & -80 & 0.65 & 12.1 & 11.6 & 11.7 & 11.8 & 0.02 \\
\hline-100 & 0.50 & 10.5 & 10.7 & 10.8 & 10.7 & 0.01 & -100 & 0.65 & 11.4 & 11.0 & 11.1 & 11.2 & 0.02 \\
\hline-120 & 0.50 & 9.8 & 10.0 & 10.2 & 10.0 & 0.02 & -120 & 0.65 & 10.7 & 10.4 & 10.5 & 10.5 & 0.02 \\
\hline-140 & 0.50 & 9.1 & 9.3 & 9.6 & 9.3 & 0.03 & -140 & 0.65 & 10.0 & 9.7 & 9.9 & 9.9 & 0.02 \\
\hline-165 & 0.50 & 8.2 & 8.4 & 8.8 & 8.5 & 0.04 & -165 & 0.65 & 9.2 & 8.9 & 9.2 & 9.1 & 0.02 \\
\hline \multirow[t]{2}{*}{$T\left({ }^{\circ} \mathrm{C}\right)$} & \multirow[t]{2}{*}{$\mid f_{\mathrm{t}} / f_{\mathrm{tk}}$ ratio } & \multicolumn{5}{|c|}{$\alpha_{t}$ in Group E $\left(\times 10^{-6} /{ }^{\circ} \mathrm{C}\right)$} & $T\left({ }^{\circ} \mathrm{C}\right)$ & $\mid f_{\mathrm{t}} / f_{\mathrm{tk}}$ ratio & \multicolumn{5}{|c|}{$\alpha_{t}$ in Group E $\left(\times 10^{-6} /{ }^{\circ} \mathrm{C}\right)$} \\
\hline & & E1 & E2 & E3 & Mean & C.O.V. & & & E1 & E2 & E3 & Mean & C.O.V. \\
\hline 0 & 0.75 & 14.8 & 14.7 & 15.2 & 14.9 & 0.02 & -100 & 0.75 & 11.6 & 11.5 & 11.4 & 11.5 & 0.01 \\
\hline-20 & 0.75 & 14.2 & 14.1 & 14.4 & 14.2 & 0.01 & -120 & 0.75 & 11.0 & 10.9 & 10.6 & 10.8 & 0.02 \\
\hline-40 & 0.75 & 13.6 & 13.4 & 13.7 & 13.6 & 0.01 & -140 & 0.75 & 10.4 & 10.2 & 9.9 & 10.2 & 0.02 \\
\hline-60 & 0.75 & 12.9 & 12.8 & 12.9 & 12.9 & 0.01 & -165 & 0.75 & 9.6 & 9.4 & 8.9 & 9.3 & 0.04 \\
\hline-80 & 0.75 & 12.3 & 12.1 & 12.2 & 12.2 & 0.01 & & & & & & & \\
\hline
\end{tabular}

steel strand increases almost linearly with the increase of the temperature from -165 to $0{ }^{\circ} \mathrm{C}$, e.g., the $\alpha_{\mathrm{m}}$ value for steel strand with $0.4 f_{\mathrm{t}} / f_{\mathrm{tk}}$ prestressing level was increased by 4,6 , $9,11,14,17,19$, and $22 \%$ as the temperature increased from -165 to $-120^{\circ} \mathrm{C},-100,-80,-60,-40,-20$, and $0{ }^{\circ} \mathrm{C}$, respectively. Moreover, the increase of the prestressing levels also increase the average thermal expansion coefficient, e.g., at $-120{ }^{\circ} \mathrm{C}$ the $\alpha_{\mathrm{m}}$ value was, respectively, increased by $14,17,21$, and $28 \%$ as the prestressing level increased from 0 to $0.4,0.5,0.65$, and $0.75 f_{\mathrm{t}} / f_{\mathrm{tk}}$.

Thus, these two parameters need to be included in the analysis on the average thermal expansion of the steel strand.

\section{Analysis and discussion}

Previous experimental results showed that the linear expansion coefficients were significantly influenced by the low temperature level, $T$, and prestressing level, $\beta_{p}=f_{\mathrm{t}} / f_{\mathrm{tk}}$. This section makes efforts to build the analytical relationship between the transit linear expansion coefficient, $\alpha_{t}$ (or average linear expansion coefficient, $\alpha_{m}$ ) of the steel strand and the boundary condition that includes the temperature level, $T$, and prestressing level, $\beta_{p}$. The test data listed in Tables 2 and 3 were used in this development of the mathematical expressions through the regression analysis method. 
Table 3 Average linear thermal expansion coefficients for steel strands under different low temperature and prestressing stress.

\begin{tabular}{|c|c|c|c|c|c|c|c|c|c|c|c|}
\hline Group & Temp & 20 to $0^{\circ} \mathrm{C}$ & $\begin{array}{c}20 \text { to } \\
-20^{\circ} \mathrm{C} \\
\end{array}$ & $\begin{array}{c}20 \text { to } \\
-40{ }^{\circ} \mathrm{C} \\
\end{array}$ & $\begin{array}{c}20 \text { to } \\
-60{ }^{\circ} \mathrm{C} \\
\end{array}$ & $\begin{array}{c}20 \text { to } \\
-80^{\circ} \mathrm{C} \\
\end{array}$ & $\begin{array}{c}20 \text { to } \\
-100^{\circ} \mathrm{C} \\
\end{array}$ & $\begin{array}{c}20 \text { to } \\
-120^{\circ} \mathrm{C} \\
\end{array}$ & $\begin{array}{c}20 \text { to } \\
-140^{\circ} \mathrm{C} \\
\end{array}$ & $\begin{array}{c}20 \text { to } \\
-165^{\circ} \mathrm{C} \\
\end{array}$ & $\begin{array}{l}\text { Mean/ } \\
\text { C.O.V. }\end{array}$ \\
\hline \multirow[t]{3}{*}{ A } & $\alpha_{\mathrm{m}, \mathrm{T}}$ & 12.1 & 11.8 & 11.5 & 11.2 & 10.9 & 10.6 & 10.3 & 10.0 & 9.6 & - \\
\hline & $\alpha_{\mathrm{m}, \mathrm{P}}$ & 12.0 & 11.8 & 11.6 & 11.3 & 11.1 & 10.8 & 10.5 & 10.2 & 9.7 & - \\
\hline & $\mathrm{T} / \mathrm{P}$ & 1.01 & 1.00 & 0.99 & 0.99 & 0.98 & 0.98 & 0.98 & 0.98 & 0.99 & $0.99 / 0.01$ \\
\hline \multirow[t]{3}{*}{ B } & $\alpha_{\mathrm{m}, \mathrm{T}}$ & 13.9 & 13.6 & 13.3 & 13.0 & 12.7 & 12.4 & 12.1 & 11.8 & 11.4 & - \\
\hline & $\alpha_{\mathrm{m}, \mathrm{P}}$ & 13.6 & 13.4 & 13.1 & 12.9 & 12.6 & 12.3 & 11.9 & 11.6 & 11.0 & - \\
\hline & $\mathrm{T} / \mathrm{P}$ & 1.02 & 1.01 & 1.02 & 1.01 & 1.01 & 1.01 & 1.02 & 1.02 & 1.04 & $1.02 / 0.01$ \\
\hline \multirow[t]{3}{*}{$\mathrm{C}$} & $\alpha_{\mathrm{m}, \mathrm{T}}$ & 14.4 & 14.1 & 13.7 & 13.4 & 13.1 & 12.7 & 12.4 & 12.0 & 11.6 & - \\
\hline & $\alpha_{\mathrm{m}, \mathrm{P}}$ & 14.1 & 13.8 & 13.6 & 13.3 & 13.0 & 12.7 & 12.3 & 12.0 & 11.4 & - \\
\hline & $\mathrm{T} / \mathrm{P}$ & 1.02 & 1.02 & 1.01 & 1.01 & 1.01 & 1.00 & 1.01 & 1.00 & 1.02 & $1.01 / 0.01$ \\
\hline \multirow[t]{3}{*}{$\mathrm{D}$} & $\alpha_{\mathrm{m}, \mathrm{T}}$ & 14.7 & 14.4 & 14.1 & 13.7 & 13.4 & 13.1 & 12.8 & 12.5 & 12.1 & - \\
\hline & $\alpha_{\mathrm{m}, \mathrm{P}}$ & 14.8 & 14.5 & 14.2 & 14.0 & 13.7 & 13.3 & 12.9 & 12.5 & 12.0 & - \\
\hline & $\mathrm{T} / \mathrm{P}$ & 0.99 & 0.99 & 0.99 & 0.98 & 0.98 & 0.98 & 0.99 & 1.00 & 1.01 & $0.99 / 0.01$ \\
\hline \multirow[t]{3}{*}{$\mathrm{E}$} & $\alpha_{\mathrm{m}, \mathrm{T}}$ & 15.3 & 14.9 & 14.6 & 14.2 & 13.9 & 13.6 & 13.2 & 12.9 & 12.4 & - \\
\hline & $\alpha_{\mathrm{m}, \mathrm{P}}$ & 15.3 & 15.0 & 14.7 & 14.4 & 14.1 & 13.8 & 13.4 & 13.0 & 12.4 & - \\
\hline & $\mathrm{T} / \mathrm{P}$ & 1.00 & 0.99 & 0.99 & 0.99 & 0.99 & 0.99 & 0.99 & 0.99 & 1.00 & $1.02 / 0.01$ \\
\hline
\end{tabular}

$\alpha_{\mathrm{m}, \mathrm{T}}$ denotes experimental average thermal expansion coefficient; $\alpha_{\mathrm{m}, \mathrm{P}}$ denotes predicted average thermal expansion coefficient by Eq. (6); T/P denotes test-to-predciton ratio, i.e., $\alpha_{\mathrm{m}, \mathrm{T}} / \alpha_{\mathrm{m}, \mathrm{P}}$.

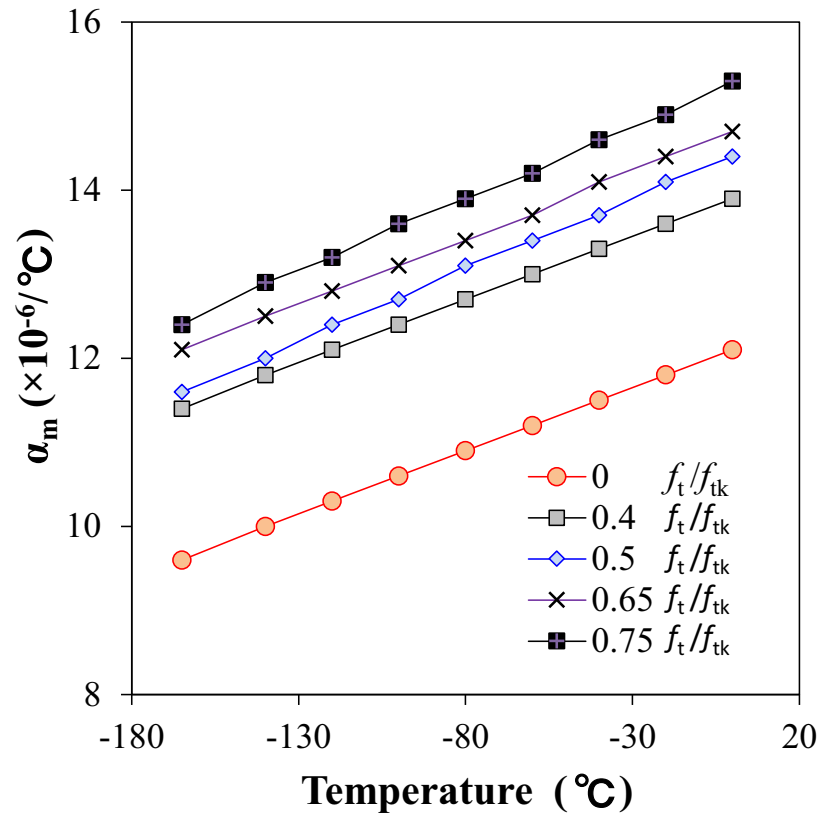

Fig. 6 Scatters of average linear expansion coefficient versus temperature relationship.

Considering the influences of $T$ and $\beta_{p}$ on $\alpha_{t}$ and $\alpha_{m}$ were in the form of the increasing or reduction factors between 0 and 1 or slightly larger than 1.0, general exponential models were adopted in this regression analysis. Since, the test results confirmed the importance of these two key parameters, the assumed exponential model are as the following

$$
\begin{aligned}
& \alpha_{t}=A T^{B} e^{C \beta_{P}} \\
& \alpha_{\mathrm{m}}=D T^{E} e^{F \beta_{P}}
\end{aligned}
$$

where $\mathrm{A}, \mathrm{B}, \mathrm{C}, \mathrm{D}, \mathrm{E}$, and $\mathrm{F}$ are constants that can be obtained from the regression analysis; $T$ denotes temperature, in $\mathrm{K} ; \beta_{p}$ denotes prestressing levels.

The logarithmic transformations on Eqs. (3) and (4) were carried out to facilitate the linear regression analyses to these two models. Regarding the selection of the predictor subset from the regression analysis, there are many available methods that include stepwise regression method, forward selection method, backward elimination method, and best subset method (Cohen et al. 2003; Miller 1990). This paper utilized the best subset method to evaluate the importance of the predictors for the thermal expansion coefficient of the steel strand used in the pretressed reinforced concrete structures, and select the proper subset of predictors to develop a regression model with satisfactory predicting ability. The indexes in the best subset method to evaluate the fitting of the regression model include standard error of the regression, $S$, the correlation coefficient, $R^{2}$, and Mallows $\mathrm{C} p$ index (Mallows 1995). The standard error, $S$, usually is an estimate of the standard deviation of prediction data that describes the accuracy of the regression model. The correlation coefficient $R^{2}$ describes the proportion of the test data could be described by the developed regression model that is a value between 0 and 1.0. For the developed regression model with $p$ predictors from total $n$ predictors $(p<n)$, the variable subsets with lower Mallows $\mathrm{C} p$ values (not bigger 
than $p$ ) indicates preferable subset (Mallows 1995; Cohen et al. 2003; Thompson 1978; Mallows 1973).

By satisfying the above three evaluation criteria, the regression analyses were carried out with the best subset method. Different possible combinations of the predictors were considered, and regression results are listed in Table 4. Based on these regression analyses, some observations are summarized as the following;

(a) The regression analyses on $\alpha_{t}$ and $\alpha_{m}$ show that the regression models with two predictors, i.e., low temperature $T$ and prestressing level $\beta_{P}$ offer much higher correlations and much more lower Mallows $\mathrm{Cp}$ values, which indicates the better models than that with one predictor.

(b) Through satisfying the above described criteria, the regressions models $3 \mathrm{AT}$ and 6AM in Table 4 were recommended for the prediction purposes for the steel strand under combined low temperature and prestressing stress. These two models exhibited largest correlation coefficients $R^{2}(0.98$ for model 3AT and 0.99 for model 6AM), smallest standard errors $S$ (0.02 for model 3AT and 0.01 for model 6AM), and smallest Mallow Cp values (3 for both model 3AT and 6AM) among three models in each group.

The recommended mathematical models to calculate the linear expansion coefficients of the steel strands under combined low temperatures and prestressing stresses are as follows;

$$
\begin{aligned}
& \alpha_{\mathrm{t}}=0.575 T^{0.534} e^{0.354 \beta_{P}} \\
& \alpha_{\mathrm{m}}=3.353 T^{0.227} e^{0.322 \beta_{P}}
\end{aligned}
$$

where $\alpha_{\mathrm{t}}$ and $\alpha_{\mathrm{m}}$ denote transit and average linear expansion coefficient of the steel strand under combined low temperature and prestressing stress, in $10^{-6} /{ }^{\circ} \mathrm{C} ; T=$ temperature, in $\mathrm{K}$, and $128 \mathrm{~K} \leq T 293 \mathrm{~K} ; \beta_{P}$ denotes prestress levels and equals $f_{t} / f_{t k}$, and it is a value between 0 and 1.0

Figures 7 and 8 compare the predictions on the transit and average linear expansion coefficients by Eqs. (5) and (6) with those test data. The comparisons show that the developed mathematical models could accurately describe the relationship between the linear expansion coefficients of the steel strand and low temperature as well as prestressing

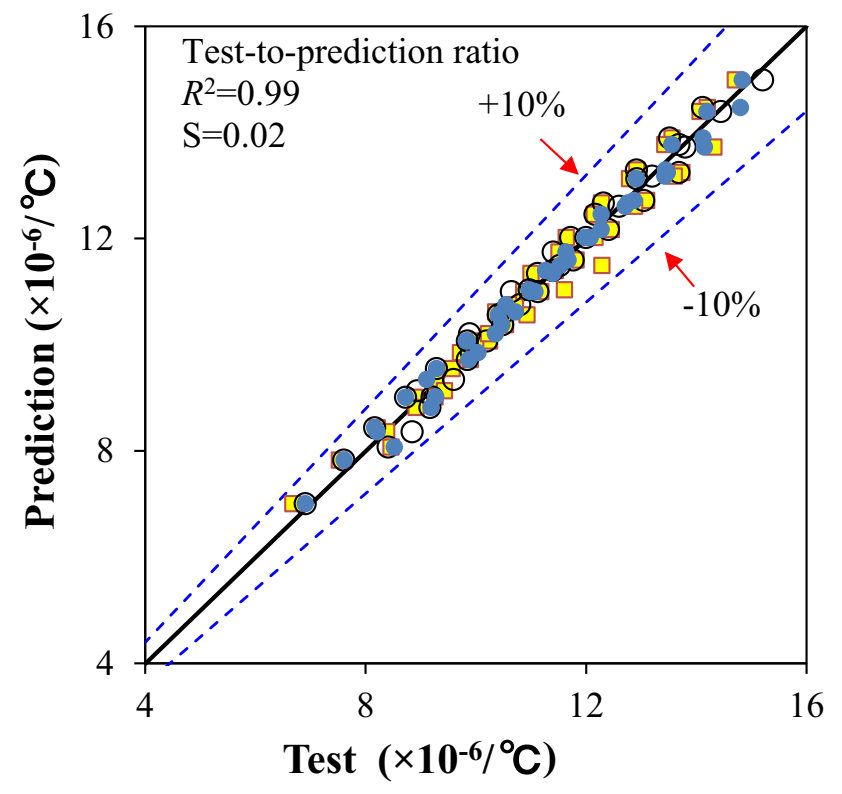

Fig. 7 Comparisons of transit linear thermal expansion coefficient $\alpha_{t}$ between tests and predictions.

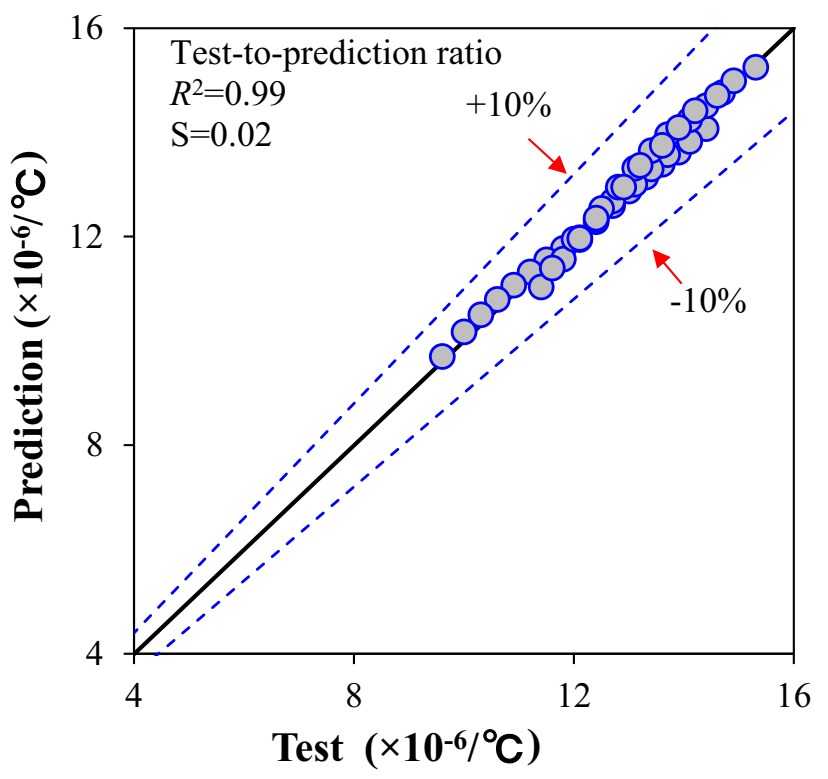

Fig. 8 Comparisons of average linear thermal expansion coefficient $\alpha_{m}$ between tests and prediction.

\begin{tabular}{|c|c|c|c|c|c|c|c|}
\hline Response & Model & $\mathrm{n}$ & $R^{2}$ & Mallows $\mathrm{C} p$ & $S$ & $\ln T$ & $\beta_{P}$ \\
\hline \multirow[t]{3}{*}{$\alpha_{t}$} & $1 \mathrm{AT}$ & 1 & 0.73 & 1024 & 0.10 & & $\mathrm{x}^{\mathrm{a}}$ \\
\hline & $2 \mathrm{AT}$ & 1 & 0.24 & 2935 & 0.16 & $\mathrm{x}$ & \\
\hline & $3 \mathrm{AT}$ & 2 & 0.98 & 3 & 0.02 & $\mathrm{x}$ & $\mathrm{x}$ \\
\hline \multirow[t]{3}{*}{$\alpha_{m}$} & 4AM & 1 & 0.60 & 1042 & 0.07 & & $\mathrm{x}$ \\
\hline & $5 \mathrm{AM}$ & 1 & 0.36 & 1067 & 0.09 & $\mathrm{x}$ & \\
\hline & $6 \mathrm{AM}$ & 2 & 0.99 & 3 & 0.01 & $\mathrm{x}$ & $\mathrm{x}$ \\
\hline
\end{tabular}

Table 4 The best subset regression analysis of $\ln \alpha_{\mathrm{t}}\left(\right.$ or $\ln \alpha_{\mathrm{m}}$ ) on $\ln T$ and $\beta_{P}$.

${ }^{\mathrm{a}}$ Denotes considered predictors in the subset regression analysis; $n$, number of considered predictors. 
levels. All the predictions were within the scope of $\pm 10 \%$ errors.

Thus, Eqs. (5) and (6) are recommended to predict the transit and average linear expansion coefficients of the steel strand under low temperatures of 20 to $-165^{\circ} \mathrm{C}$.

However, the developed design equations, i.e., Eqs. (5) and (6) were only developed based on the test data reported in this paper. Further validation by more test data reported by other researchers are still required that will be performed in future research.

\section{Conclusions}

This paper firstly reported the test results on the thermal expansion coefficient of the steel strand used in the PC structure under combined different low temperature and prestressing levels. The transit and average linear expansion coefficients of the steel strand under different low temperatures varying from 20 to $-165{ }^{\circ} \mathrm{C}$ and prestressing levels ranging from 0 to $0.75 f_{t} / f_{t k}$. The influences of the low temperature and prestressing levels on the thermal expansion behaviours of the steel strand were discussed and analyzed. Based on the test results, regression analyses were also carried out to develop the regression models. Based on these experimental and analytical studies, the following observations and conclusions were drawn;

The decrease of the temperature from 20 to $-160{ }^{\circ} \mathrm{C}$ significantly reduces the transit and average linear expansion coefficients of the steel strand. As the temperature decreases from 20 to $-160{ }^{\circ} \mathrm{C}$, transit linear expansion coefficient $\alpha_{t}$ was, respectively, decreased by $42,37,40,37$, and $38 \%$ for the steel strand under prestressing levels of $f_{t} / f_{t k}$ equalling 0 , $0.4,0.5,0.65$, and 0.75 whilst the $\alpha_{\mathrm{m}}$ was averagely decreased by $21,18,20,18$, and $19 \%$ for the steel strand with prestressing levels of $f_{t} / f_{t k}=0,0.4,0.5,0.65$, and 0.75 , respectively.

Increasing the prestressing stress applied on the steel strand leads to the increases of both transit and average linear expansion coefficient of the steel strand under different low temperature levels. As the prestressing level ratio of $f_{t} / f_{t k}$ increases from 0.0 to 0.75 , the $\alpha_{\mathrm{t}}$ (or $\alpha_{\mathrm{m}}$ ) value was averagely increased by about $26-37 \%$ (or 26-29\%) for the steel strand under different low temperatures varying from 0 to $-160{ }^{\circ} \mathrm{C}$.

Based on the reported test data, regression models, i.e., Eq. (5) and (6) were developed for the predictions on the transit and average linear expansion coefficients of the steel strand under low temperature interval of 0 to $-165{ }^{\circ} \mathrm{C}$ and different prestressing levels of 0.0 to $0.75 f_{t} / f_{t k}$. The validations of the predictions by the developed models against the test results confirmed the good accuracy of the proposed regression models.

Equations (5) and (6) were recommended to predict the transit and average linear expansion coefficient under combined low temperature within of 0 to $-165^{\circ} \mathrm{C}$ and prestressing levels of 0.0 to $0.75 f_{t} / f_{t k}$. However, the test results and developed regression models were only based on limited test data, and these experimental observations and developed models maybe only applicable at these certain conditions. Further validations maybe still required for the design purposes.

\section{Acknowledgements}

This work was financially funded by the National Natural Science Foundation of China entitled "Experimental study on material properties and structural behavior of prestressed concrete at cryogenic temperatures" (Project No. 51478309). The authors gratefully express their gratitude for the supports.

\section{Open Access}

This article is distributed under the terms of the Creative Commons Attribution 4.0 International License (http:// creativecommons.org/licenses/by/4.0/), which permits un restricted use, distribution, and reproduction in any medium, provided you give appropriate credit to the original author(s) and the source, provide a link to the Creative Commons license, and indicate if changes were made.

\section{References}

American Institute of Steel Construction (AISC). (1994). Manual of steel construction: Load and resistance factor design, 2nd Ed., Vol. I, Structural members, specifications and codes, Chicago.

ASCE. (1996). Structural applications of steel sables for buildings. New York: ASCE.

Chen, Z. H., \& Liu, Z. S. (2010). Experimental research of linear thermal expansion coefficient of cables. Journal of Building Materials, 13(5), 626-631.

Cohen, J., Cohen, P., West, S. G., \& Aiken, L. S. (2003a). Applied multiple regression/correlation analysis for the behavioral sciences (3rd ed.). Mahwah: Lawrence Erlbaum.

Cohen, J., Cohen, P., West, S. G., \& Aiken, L. S. (2003b). Applied multiple regression/correlation analysis for the behavioral sciences (3rd ed.). Mahwah: Lawrence Erlbaum.

Elices, M., Corres, H., \& Planas, J. (1986). Behaviour at cryogenic temperatures of steel for concrete reinforcement. Journal Proceedings, 83(3), 405-411.

Elices, M., Rostasy, F. S., Faas, W. M., \& Wiedemann, G. (1982). Cryogenic behaviour of materials for prestressed concrete FIP State-of-the-Art Report. Slough: Wexham Spring.

Eurocode3. (2006). Design of steel structures-Part 1-11: Design of structures with tension components. BS EN 1993-1-11, British Standards Institution, London. 
Gasparin, I. D., \& Gautam, V. (2002). Geometrically nonlinear static behavior of cable structures. Journal of Structural Engineering, 128(10), 1317-1329.

International Federation for Structural Concrete. (2010). Fib model code for concrete structures. Swissland: Laussane.

Japanese Steel Structure Association. (1994). Cable material specification used in structure. JSS II 03-1994, Japan.

Liu, J., Li, N., \& Chen, Z. H. (2007). Experiment study on the linear expansion factor of cables. Low Temperature Architecture Technology, 1, 54-55. (in Chinese).

Mallows, C. L. (1973). Some comments on Cp. American Statistical Association, Technometrics, 15(4), 661-675.

Mallows, C. L. (1995). More comments on Cp. American Statistical Association, Technometrics, 37(4), 362-372.

Miller, A. J. (1990). Subset selection in regression. London: Chapman and Hall.

National Standard of the People's Republic of China, GB/ T4339-2008. Test methods for thermal expansion characteristic parameters of metallic materials, China.

Nie, Z. M. (2012). Experimental study on bonding properties between steel wire and concrete or cement slurry at cryogenic temperatures. Master Thesis, Tianjin University, China; 2012.
Palmer, A., \& Croasdale, K. (2013). Arctic offshore engineering. Singapore: World Scientific Publishing.

Planas, J., Corres, H., \& Elices, M. (1988). Behaviour at cryogenic temperatures of tendon anchorages for prestressing concrete. Materials and Structures, 21(4), 278-285.

Sun, G. J., Chen, Z., \& Liu, Z. (2011). Analytical and experimental investigation of thermal expansion mechanism of steel cables. ASCE Journal of Materials in Civil Engineering, 23(7), 1017-1027.

Thompson, M. L. (1978). Selection of variables in multiple regression: part I. A review and evaluation. International Statistical Review, 46, 1-19.

Yan, J. B., Liew, J. Y. R., Zhang, M. H., \& Wang, J. Y. (2014). Mechanical properties of normal strength mild steel and high strength steel S690 in low temperature relevant to Arctic environment. Materials and Design, 61, 150-159.

Yan, J. B., \& Xie, J. (2017). Experimental studies on mechanical properties of steel reinforcements under cryogenic temperatures. Construction and Building Materials, 151, 661-672. 